\title{
The rhetoric of female sexual dysfunction: faux feminism and the FDA
}

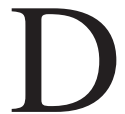

espite the most familiar uses of the term, rhetoric is not speech at odds with reality. Rather, it is the art of persuasion itself. Its study dates back to ancient Greece, and its terms of analysis remain generative. The rhetorical analyst's central question, always specified for situation, is "Who is persuading whom of what, and what are the means of persuasion?"1 Rhetoric is a regular part of medicine: in the absence of positive diagnostic tests, patients may have to persuade physicians that they are ill and in need of care; physicians must sometimes persuade patients to adhere to courses of treatment; illness anxiety, perhaps fuelled by the Internet, may lead people to persuade themselves that they are ill; and multiple forces converge to persuade us that some conditions count as disease states, while others do not.

A current example of medical rhetoric in action is the case of flibanserin, a drug currently under review for the third time - the next decision is imminent by the US Food and Drug Administration (FDA). Flibanserin is offered for the treatment of female hypoactive sexual desire disorder, a type of sexual dysfunction. In October 2014, the FDA held patient-focused, information-gathering meetings on female sexual dysfunction. I attended those meetings to observe firsthand the persuasive strategies at work on a regulatory body understood to adjudicate cases on the basis of scientific evidence. In the course of events (at these meetings and since), it has become clear that Sprout Pharmaceuticals, owners of flibanserin, and allied individuals and groups likely have persuaded the FDA to take matters outside scientific evidence into account in its decision-making.

In advance of the October meetings, a massive pro-drug media campaign, ${ }^{2}$ including an active website (eventhe-

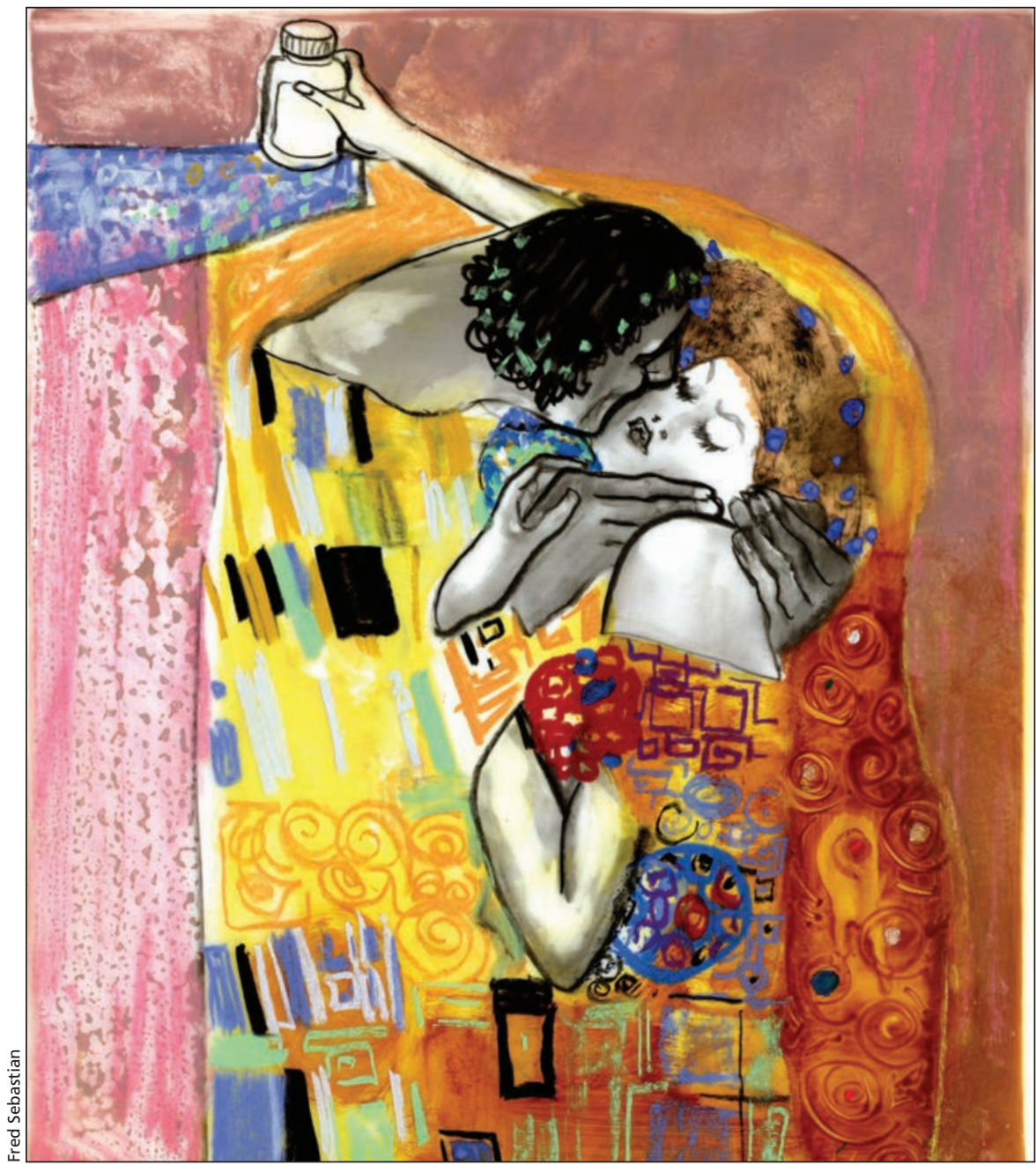

score.org), was launched, with the support of groups that prominently include Sprout. Even the Score most saliently equates non-approval of a drug for female sexual dysfunction with FDA bias against women. Its main argument: If men have drugs for improving sexual function, women should have them too. The claim is problematic for many reasons. For example, the site claims erroneously that 26 drugs are approved for men. Most important, Even the Score appears to ignore the fact that, despite the efforts of pharmaceutical companies over several years, no drug for female sexual dysfunction has been developed that, on the evidence, meets FDA standards for safety and efficacy. Although Even the Score's reasoning has the sound of a feminist argument, it is rather a cooptation of a feminist principle. The bid to "even the score" acts rhetorically to shift the ground of debate from medical evidence to sexism, from reason to popular appeal.

On Feb. 17, 2015, Sprout Pharma- 
ceuticals submitted its reapplication for approval of flibanserin. On June 4, expert panelists advising the FDA voted 18 to 6 to approve it "with risk management options." The FDA's final decision is expected by Aug. 18 (the FDA can override the vote of an expert panel, although it seldom does). If the decision is to approve the drug, it will appear that the FDA was influenced by Sprout and its allies, and influenced too by public opinion. In part through the efforts of Even the Score, there is widespread belief that a "pink Viagra" exists and that, on the principle of gender equity, it should be available to women. (Flibanserin, though, is no "pink Viagra"; for example, the pill must be taken daily, not "as needed," so adverse effects are a special concern. "Viagra" is only a metaphor here, evoking by association the idea of good sex on demand.)

If the drug fails to win approval, some credit must go to groups such as the New View Campaign that have marshalled more scientific evidence and their own rhetorical resources to influence public opinion and make the case to the FDA that it should not approve a drug that does not meet rigorous standards of safety and efficacy. ${ }^{3}$

Certainly, disappointing sex lives and the figure of the "frigid" woman have been around for a long time. But the turn of this century marked a very public moment in the medicalization of $\operatorname{sex}^{4}$ and pathologization of low desire. Over the past 15 or so years - arguably since the FDA approval of Viagra in 1998 and the publication of a JAMA article in 1999 claiming that $43 \%$ of women experience sexual dysfunction ${ }^{5}$ - many women who experience low sexual desire have been persuaded that they may well have a medical condition.

By the time Viagra (sildenafil) came to market, the race was already on to develop a sex drug for women. Several candidate drugs tried and failed to be that drug. Among them are sildenafil itself, repurposed to increase bloodflow to female genitals; Intrinsa, a testosterone patch for women; and flibanserin, aimed at women's brains. According to Stephen Stahl, adjunct professor of psychiatry at the University of California
San Diego, "Flibanserin is believed to work by correcting [a neurochemical] imbalance and providing the appropriate areas of the brain with a more suitable mix of brain chemicals to help restore sexual desire." Each of these drugs is premised on a different theory about the cause of female sexual dysfunction. This inconsistency itself might throw into question the very nature of low desire, but many forces are at work - some professional, ${ }^{5}$ some corporate ${ }^{7}$ and some popular ${ }^{2}$ - to persuade women that low desire is abnormal and may be a sign of biological disease.

At its October meeting, the FDA seemed already to be caught up in the logic of Even the Score and had agreed to feature prominently on its roster of speakers both "patients" and "experts" associated with the campaign. It seemed clear from the language of FDA moderators that certain questions were taken to have already been asked and answered: low sexual desire was, for many women, a biological disease, and there was an "unmet need" for pharmaceutical treatment of it. The prodrug campaign had ensured that most of the testimony the FDA would hear came from married women who had no interest in sex with their husbands and felt themselves to have a biological disease that was, moreover, threatening their marriages. Eight women testified; six of them told deeply personal stories that ended with an emotional call for drugs. From compulsory disclosures of sponsorship, it emerged that Sprout itself or Veritas (a marketing firm connected to Sprout) paid the expenses of some panelists and countless other attendees, most of whom wore matching teal scarves and Even the Score and \#WomenDeserve buttons. ${ }^{8}$

The women who testified were addressed by FDA moderators as "patients" - as people already constituted as having disease - rather than, for example, as people with unresolved relationship issues or a history of sexual repression or a life with work and children that left little energy for sex. Moderators asked these women about their "symptoms," a term also assuming the presence of disease. Notably, the word "pleasure" was not used in two days of meetings: for some women who reported their experience, sexual distress was, in the first instance, proxy distress, and a "satisfying sexual event" (calculated by self-report as a measure for the treatment outcome) counted as satisfying when their husbands were happy after it was over.

We all experience distress in the terms available for us to experience it in, and sexual distress is no different. We are surrounded by professional and public discourses - rhetorics - about health and illness. These rhetorics are imbued with values, including values about sex. We absorb these values and draw on them in interpreting our own experience of health and illness. Rhetorical study is one means of getting at the processes by which we become persuaded, sometimes inappropriately, that our distress is best thought of as contained in our individual bodies, expressing a disease, in need of a drug.

\section{Judy Z. Segal PhD}

Professor, Department of English, University of British Columbia,

Vancouver, BC

\section{References}

1. Segal JZ. Health and the rhetoric of medicine. Carbondale (IIl): Southern Illinois University Press; 2005.

2. Schiavocampo M, Jesko J, Effron L. Fight over 'little pink pill' raises sexism questions. ABC News: Nightline 2014 May 21. Available: http://abcnews.go.com /Health/fight-pink-pill-boosting-womens-sex-drive -raises/story?id=23813586 (accessed 2014 Oct. 20).

3. Mintzes B, Tiefer L. We shouldn't push dubious 'pink Viagra' pills on women and call it emancipation. The Guardian [London] 2015 June 4. Available: www.theguardian.com/commentisfree/2015/jun/05/ women-sex-viagra-flibanserin-fda-research (accessed 2015 June 5)

4. Cacchioni T, Tiefer L. Why medicalization? Introduction to the special issue on the medicalization of sex. J Sex Res 2012;49:307-10.

5. Laumann EO, Paik A, Rosen RC. Sexual dysfunction in the United States. JAMA 1999;281:537-44.

6. Stahl S. In: Sprout Pharmaceuticals resubmits flibanserin new drug application for the treatment of hypoactive sexual desire disorder in premenopausal women [press release]. New York: PR Newswire; 2015 Feb. 17. Available: www.prnewswire.com/news /sprout+pharmaceuticals (accessed 2015 Feb. 17).

7. Raleigh (NC): Sprout Pharmaceuticals. Available: www.sproutpharma.com (accessed 2015 June 29).

8. Female sexual dysfunction patient-focused drug development public meeting. Silver Spring, MD: Food and Drug Administration Center for Drug Evaluation and Research; 2014 Oct. 27. Available: www.fda.gov/downloads/Drugs/NewsEvents/ UCM423113.pdf (accessed 2015 Aug 7).

Competing interests: Judy Segal's research grant from the Social Sciences and Humanities Research Council covered costs of travel to the FDA.

CMAJ 2015. DOI:10.1503/cmaj.150363 